\title{
Help for the Independent Retailer
}

\section{Some useful addresses}

Alliance of Independent Retailers

Newton Road

Worcestershire

0905-28165

British Retailers Association

Commonwealth House

1/19 New Oxford Street

London WC1A 1PA

01-4040955

National Association of Shopkeepers

Lynch House

91 Mansfield Road

Nottingham NG1 3FN

0602-475046

Independent Footwear Retailers

Association

New Ash Green

Dartford

Kent DA3 8QY

0474-874704

National Federation of Retail Newsagents

Yeoman House

Selforde Street

London EC1R OHD

01-253 4255
British Franchise Association

Franchise Chambers

75a Bell Street

Henley-on-Thames

Oxon RG9 2BD

0491-578049

Institute of Grocery Distribution

Letchmore Heath

Watford

Herts WD2 8DQ

0927-67141

Retail Consortium

Commonwealth House

1/19 New Oxford Street

London WC1A 1PA

01-404 4622 